\title{
CRESCIMENTO E OXIDAÇÃO DE EXPLANTES DE BANANEIRA-PRATA (Musa AAB) IN VITRO. I. CONCENTRAÇÕES DE SAIS DE FERRO, COBRE E ZINCO ${ }^{1}$
}

\author{
SERGIO UTINO², IRAÍDES FERNANDES CARNEIRO³ ${ }^{3}$ LÁZARO JOSÉ CHAVES ${ }^{3}$
}

\begin{abstract}
RESUMO - Este experimento teve como objetivo avaliar a influência de diferentes concentrações de ferro, cobre e zinco do meio MS (MURASHIGE \& SKOOG, 1962) no controle da oxidação de explantes iniciais de bananeira-Prata (Musa AAB). Foram utilizadas três concentrações $(100,50$ e $0 \mu \mathrm{M})$ de FeEDTA, duas concentrações $(0,1$ e $0 \mu \mathrm{M})$ de $\left(\mathrm{CuSO}_{4}\right) \cdot 5 \mathrm{H}_{2} \mathrm{O}$ e duas concentrações $(30$ e $0 \mu \mathrm{M})$ de $\left(\mathrm{ZnSO}_{4}\right) \cdot 7 \mathrm{H}_{2} \mathrm{O}$, num delineamento inteiramente casualizado, arranjado em um fatorial completo $3 \times 2 \times 2$, utilizando-se de 15 repetições. Ápices caulinares foram inoculados em meio MS modificado e, decorridos 28 dias após a inoculação, avaliaram-se a massa de matéria fresca, altura e grau de oxidação. Observou-se que esses micronutrientes são essenciais para o crescimento dos explantes e que a concentração de ferro influencia na oxidação de explantes, sendo que maiores graus de escurecimento foram observados nas concentrações mais elevadas. A redução ou retirada destes elementos do meio MS, isoladamente ou em combinações, não foi suficiente para eliminar a oxidação dos explantes.
\end{abstract}

Termos para indexação: cultura de tecidos, Musa AAB, oxidação fenólica, ferro, cobre, zinco.

\section{EXPLANTS GROWTH AND OXIDATION OF BANANA CV. PRATA (Musa AAB) IN VITRO. I. IRON, COPPER, AND ZINC SALT CONCENTRATIONS.}

\begin{abstract}
This research work was carried to verify the effects of salt concentrations with iron, copper and zinc of the MS (MURASHIGE \& SKOOG, 1962) medium on explants oxidation control for banana plants, cv. Prata (Musa AAB). Three salt concentrations $(100,50,0 \mu \mathrm{M})$ of FeEDTA and two concentrations $(100,0 \mu \mathrm{M})$ of $\left(\mathrm{CuSO}_{4}\right) .5 \mathrm{H} 2 \mathrm{O}$ and two concentration $(30 \mathrm{e} 0 \mu \mathrm{M})$ of $\left(\mathrm{ZnSO}_{4}\right) .7 \mathrm{H} 2 \mathrm{O}$ were utilized. Completely randomized in a $3 \times 2 \times 2$ factorial scheme with fifteen repetitions were utilized. Shoot tip apices were inoculated in MS medium. Explants fresh matter weight, height and oxidation grade were evaluated 28 days after inoculation. It was observed that iron, copper and zinc are essential to explants growth. Iron concentration reduction caused decrease in oxidation grade, the reduction or elimination of iron, copper and zinc in MS medium, isolated or in combination forms was not sufficient to eliminate the oxidation grade.
\end{abstract}

Index terms: tissue culture, Musa $\mathrm{AAB}$, phenolic oxidation, iron, copper and zinc.

\section{INTRODUÇÃO}

Dentre as frutas tropicais, a banana é considerada uma das mais consumida no mundo, ocupando o segundo lugar em área cultivada, no Brasil (IBGE, 1998). Em Goiás, a bananeira foi à atividade principal dentro da fruticultura, em 1996, sendo que a banana-Prata ocupa o terceiro lugar na preferência do consumidor (CEASA, 1996).

A bananeira é propagada vegetativamente, sendo a qualidade da muda de primordial importância para o sucesso da cultura. Com o objetivo de elevar a taxa de multiplicação e reduzir a disseminação de pragas e doenças, o uso da micropropagação vem sendo estimulado no Brasil, a exemplo de outros países, grandes produtores e/ou exportadores (Vuylsteke \& Ortiz,1996; Souza et al., 1998).

Um problema freqüentemente encontrado no cultivo in vitro é o escurecimento dos tecidos lesados do explante causado pela oxidação de compostos polifenólicos (George \& Sherrington, 1984) o que prejudica o crescimento dos explantes, além de ser um fator de redução da taxa de multiplicação (Carneiro, 1997).

Os micronutrientes $\mathrm{Fe}$, $\mathrm{Cu}$ e $\mathrm{Zn}$ influenciam na oxidação de explanes, sendo $\mathrm{Fe}$ e $\mathrm{Cu}$ constituinte de enzimas as quais são liberadas quando os tecidos são lesados (Pasqual et al., 1997). O cobre faz parte das enzimas denominadas polifenoloxidase, fenolase e tirosinase (Pasqual et al., 1997) enquanto o ferro é constituinte de peroxidase (Amorim, 1985). Também desempenha papel redox, a catalase e a lacase, com ferro e cobre, respectivamente (Mengel \& Kirkby, 1987). A deficiência de zinco pode causar o aumento da atividade da polifenoloxidase $\mathrm{e}$ da peroxidase (Malavolta et al., 1974).

Após o ferimento dos tecida e conseqüente oxidação dos polifenóis há a formação de quinona, substância fitotóxica inibidora do crescimento celular (Amorim, 1985). As quinonas são substâncias altamente ativas e, posteriormente à sua produção, polimerizam e/ou oxidam proteínas para formar compostos melânicos (George \& Sherrington, 1984). Havendo a redução da produção destas enzimas oxidativas, tem-se como

1 Trabalho $n^{\circ}$ 126/2000. Recebido: 05/07/2000. Aceito para publicação: 27/06/2001. Parte da dissertação de mestrado do primeiro autor apresentada à Universidade Federal de Goiás, Goiânia, GO.

2 Eng. Agr., MS, Embrapa-Negócios Tecnológicos, CP 714, CEP 74001-970 Goiânia- GO, sntgyn@zaz.com.br.

3 Eng $^{\text {a }}$ Agr $^{\text {a }}$, Dr ${ }^{\text {a }}$, Escola de Agronomia/UFG, CP 131, CEP 74001-970 Goiânia-GO., iraides@agro.ufg.br

4 Eng. Agr., Dr., Escola de Agronomia/UFG, CP 131, CEP 74001-970 Goiânia-GO, lchaves@agro.ufg.br 
consequencia uma menor rapidez na oxidação fenólica dos tecidos lesados (Pasqual et al., 1997). É uma das formas de redução da produção destas enzimas seria uma menor absorção dos micronutrientes $\mathrm{Fe}$ e $\mathrm{Cu}$ e maior absorção de $\mathrm{Zn}$ presentes no meio de cultura.

Este trabalho teve por objetivo estudar os efeitos de concentrações de cobre, ferro e zinco sobre o crescimento e a oxidação de explantes iniciais de bananeira-Prata.

\section{MATERIAIS E MÉTODOS}

O trabalho foi conduzido no Laboratório de Cultura de Tecidos da Escola de Agronomia da Universidade Federal de Goiás. Utilizaram-se como explantes os ápices caulinares de mudas obtidas através das brotações laterais de rizomas de bananeira-Prata, colocadas em canteiro de areia para propagação rápida ex situ. Blocos contendo o meristema apical, com as dimensões de $30 \mathrm{~mm} \times 15 \mathrm{~mm} \times 15 \mathrm{~mm}$, receberam o tratamento para descontaminação, pela imersão numa solução de $35 \mathrm{ml} \mathrm{L}^{-1}$ de $\mathrm{NaOCl}$ acrescido de 30 gotas de Tween-20 L ${ }^{-1}$, durante 20 minutos. Em condições assépticas, os explantes foram lavados por três vezes com água destilada, deionizada e autoclavada, após o que, procedeu-se à redução do explante para $10 \mathrm{~mm} \times 5$ $\mathrm{mm} \times 5 \mathrm{~mm}$, deixando o meristema recoberto por primórdios foliares e porção subjacente do rizoma.

Na preparação do meio de cultura, utilizou-se o meio MS (Murashige \& Skoog, 1962), retirando-se completamente ou parte do ferro, do cobre e do zinco, conforme a Tabela 1. Ao meio, foram acrescentados sacarose $\left(30 \mathrm{~g} \mathrm{~L}^{-1}\right)$, mio-inositol (100 $\left.\mathrm{mg} \mathrm{L}^{-1}\right)$ e BAP $\left(1,0 \mathrm{mg} \mathrm{L}^{-1}\right)$. O meio teve o $\mathrm{pH}$ ajustado para 5,8 e foi solidificado com o gelan Phytagel ${ }^{\top \mathrm{M}}\left(2 \mathrm{~g} \mathrm{~L}^{-1}\right)$ para, em seguida, ser autoclavado a uma temperatura de $120^{\circ} \mathrm{C}$, pressão de $1,05 \mathrm{kgf} \mathrm{cm}^{-2}$, durante 20 minutos. Foram distribuídos $10 \mathrm{ml}$ do meio para cada tubo de ensaio, os quais foram vedados com Vitafilm (Good Year, 17 micras). Após a inoculação, os tubos de ensaio permaneceram, por uma semana, em câmara escura e, depois, foram levados para a sala de crescimento sob temperatura de $28 \pm 2^{\circ} \mathrm{C}$ com intensidade luminosa aproximada de 35 $\mu$ Einstein, por um período de 16 horas diárias.

O delineamento experimental usado foi o inteiramente casualizado, em esquema fatorial completo $3 \times 2 \times 2$ (concentrações de $\mathrm{Fe} x$ concentrações de $\mathrm{Cu} x$ concentrações de $\mathrm{Zn}$ ). Cada tratamento constituiu-se de 15 repetições, sendo que cada tubo de ensaio contendo um explante foi considerado uma repetição. A avaliação foi feita aos 28 dias após a inoculação. As características dos explantes avaliadas foram as seguintes: grau de oxidação, massa da matéria fresca $(\mathrm{g})$ e altura $(\mathrm{cm})$. A avaliação da oxidação foi efetuada subjetivamente, de forma visual, observando-se o grau de escurecimento e usando uma escala de classificação segundo a qual: $0=$ sem oxidação, $1=$ muito baixa oxidação, 2 = baixa oxidação, $3=$ oxidação intermediária e 4 = oxidação intensa.

Após a transformação para $(x+0,5)^{1 / 2}$ dos dados relativos ao grau de oxidação, estes e os demais foram submetidos à análise de variância. Quando constatada significância estatística, procedeu-se a análise de regressão ou a comparação de médias pelo teste de Tukey a $5 \%$.

\section{RESULTADOS E DISCUSSÃO}

A análise de variância mostrou que as concentrações utilizadas de $\mathrm{Fe}$ influenciaram significativamente sobre o crescimento do explante em altura, em massa da matéria fresca e sobre o grau de oxidação. A variação na concentração de $\mathrm{Cu}$ também apresentou diferença significativa em relação ao crescimento dos explantes, ao passo que o $\mathrm{Zn}$ não afetou nenhuma das características avaliadas. Diniz et al (1999) confirma a necessidade desses micronutrientes para os explantes de bananaprata anã nos primeiros 20 dias, através da absorção dos mesmos do meio de cultura. As interações $\mathrm{Fe} \times \mathrm{Cu}, \mathrm{Fe} \times \mathrm{Zn}$ e $\mathrm{Cu}$ x $\mathrm{Zn}$ foram altamente significativas para o grau de oxidação, ao passo que não influenciaram o crescimento em altura. A massa da matéria fresca foi influenciada significativamente apenas pela interação $\mathrm{Cu} \times \mathrm{Zn}$.

Pela Figura 1, verifica-se que existe um efeito linear crescente para massa da matéria fresca à medida que aumenta a concentração de $\mathrm{Fe}$ no meio de cultura. $\mathrm{O}$ ferro, considerado elemento essencial nas transformações energéticas, ocorre em proteínas do grupo heme e não-heme e está diretamente implicado no metabolismo de ácidos nucléicos e atua como ativador enzimático (Dechen et al., 1991). O ferro, de forma isolada, exerceu efeito linear sobre o grau de oxidação dos explantes sendo que, para a concentração de $5,58 \mathrm{mg} \mathrm{L}^{-1}$, os explantes receberam, em média, nota 3,14. Em contrapartida, quando o meio de cultura não continha ferro, os explantes apresentaramse pouco oxidados, recebendo, em média, nota 2,14.

Verifica-se, pela Tabela 2, que o crescimento dos explantes foi menor na ausência de $\mathrm{Cu}$, enquanto o grau de oxidação não foi influenciado pela presença deste nutriente. A retirada do $\mathrm{Cu}$ do meio $\mathrm{MS}$, portanto, não deve ser recomendada, visto que o crescimento em massa e em altura dos explantes é reduzido, sem, no entanto, reduzir o escurecimento do mesmo. A redução do crescimento em massa dos explantes, em cultivo in vitro de bananeira, pode ser prejudicial, pois levaria um maior tempo para possibilitar a divisão do explante, com o objetivo de quebra da dominância apical (Carneiro, 1997).

$\mathrm{Na}$ ausência do $\mathrm{Zn}$ e presença de $\mathrm{Cu}$, houve um aumento significativo da massa de matéria fresca; entretanto, quando o $\mathrm{Zn}$ foi mantido no meio de cultura, os explantes apresentaramse com o crescimento em massa semelhantes, tanto na presença como na ausência de $\mathrm{Cu}$. Ao analisar os efeitos significativos do $\mathrm{Cu}$ dentro das concentrações do $\mathrm{Zn}$ (Tabela 3), verifica-se que a ausência do $\mathrm{Zn}$ e do $\mathrm{Cu}$ determinou uma oxidação significativamente maior do que quando o $\mathrm{Cu}$ estava presente, ao passo que, na presença do $\mathrm{Zn}$, a oxidação foi maior com a retirada do $\mathrm{Cu}$. Na presença do $\mathrm{Cu}$, o $\mathrm{Zn}$ não causou efeito significativo na oxidação. Relacionando a massa da matéria fresca e o grau de oxidação dos explantes para os diferentes tratamentos de $\mathrm{Cu}$ e $\mathrm{Zn}$, constata-se que maior massa da matéria fresca foi alcançada quando o grau de oxidação foi menor, indicando, neste caso, que o crescimento sofreu influência negativa da oxidação, pela liberação de compostos melânicos tóxicos ao explante que inibem a atividade das enzimas (Araujo, 1995, e Pasqual et al., 1997).

$\mathrm{Na}$ interação Fe x Cu para grau de oxidação dos explantes, quando se compara dentre os níveis de Fe, constata-se que, na ausência de $\mathrm{Fe}$, a presença de $\mathrm{Cu}$ não exerceu nenhum efeito 
TABELA 1. Variação da concentração de sais contendo $\mathrm{Fe}, \mathrm{Cu}$ e $\mathrm{Zn}$ utilizadas em relação ao meio de cultura e quantidade total do nutriente. Goiânia-GO, 1999.

\begin{tabular}{|c|c|c|c|c|}
\hline \multirow{2}{*}{\multicolumn{2}{|c|}{$\begin{array}{l}\text { Variação da concentração utilizada } \\
\text { em relação ao meio de cultura }\end{array}$}} & \multicolumn{2}{|c|}{$\begin{array}{c}\text { Concentração } \\
\text { utilizada no meio M S }\end{array}$} & \multirow{2}{*}{$\begin{array}{l}\text { Total do nutriente } \\
\left(\mathrm{mg} \mathrm{L}^{-1}\right)\end{array}$} \\
\hline & & $\mathrm{mg} \mathrm{L}^{-1}$ & $\mu \mathrm{M}$ & \\
\hline \multirow[t]{3}{*}{ Fe.ED T A } & $(1 / 1)$ & 27,80 & 100 & $5,58 \mathrm{de} \mathrm{Fe}$ \\
\hline & $(1 / 2)$ & 13,90 & 50 & $2,79 \mathrm{de} \mathrm{Fe}$ \\
\hline & $(0 / 0)$ & 0 & 0 & $0,00 \mathrm{de} \mathrm{Fe}$ \\
\hline \multirow[t]{2}{*}{$\left(\mathrm{CuS}_{4}\right) \cdot 5 \mathrm{H}_{2} \mathrm{O}$} & $(1 / 1)$ & 0,025 & 0,1 & $0,006 \mathrm{de} \mathrm{Cu}$ \\
\hline & $(0 / 0)$ & 0 & 0 & $0,000 \mathrm{de} \mathrm{Cu}$ \\
\hline \multirow[t]{2}{*}{$\left(\mathrm{ZnS} \mathrm{O}_{4}\right) .7 \mathrm{H}_{2} \mathrm{O}$} & $(1 / 1)$ & 8,60 & 30 & $1,96 \mathrm{de} \mathrm{Zn}$ \\
\hline & $(0 / 0)$ & 0 & 0 & $0,00 \mathrm{de} \mathrm{Zn}$ \\
\hline
\end{tabular}

TABELA 2 - Massa da matéria fresca, altura e grau de oxidação dos explantes de bananeira-Prata (Musa AAB) na presença e ausência de cobre no meio de cultura. Goiânia-GO, 1999.

\begin{tabular}{cccc}
\hline $\begin{array}{c}\text { Cobre } \\
\left(\mathrm{mg} \mathrm{L}^{-1}\right)\end{array}$ & $\begin{array}{c}\text { M a sa d a m a téria } \\
\text { Fresca } \\
(\mathrm{g})\end{array}$ & $\begin{array}{c}\text { A 1tura do } \\
\text { ex p la te } \\
(\mathrm{cm})\end{array}$ & Graude oxidação \\
\hline 0,000 & $3,1702 \mathrm{~B}$ & $3,0585 \mathrm{~B}$ & $2,5846 \mathrm{~A}$ \\
0,006 & $3,4558 \mathrm{~A}$ & $3,7228 \mathrm{~A}$ & $2,5614 \mathrm{~A}$ \\
\hline
\end{tabular}

Médias seguidas por letras diferentes, na coluna, diferem estatisticamente a $5 \%$ de probabilidade, pelo teste de Tukey.

TABELA 3 - Médias referentes à massa da matéria fresca $(\mathrm{g})$ e grau de oxidação por explante de bananeira-Prata (Musa $\mathrm{AAB})$ na ausência e presença de cobre e zinco. Goiânia-GO, 1999.

\begin{tabular}{|c|c|c|c|c|}
\hline \multirow{3}{*}{$\begin{array}{c}\text { Cobre } \\
\left(\mathrm{mg} \mathrm{L}^{-1}\right)\end{array}$} & \multicolumn{4}{|c|}{ Zinco $\left(\mathrm{mg} \mathrm{L}^{-1}\right)$} \\
\hline & \multicolumn{2}{|c|}{ M assa da M atéria Fresca } & \multicolumn{2}{|c|}{ Grau de Oxidação } \\
\hline & 0,00 & 1,96 & 0,00 & 1,96 \\
\hline 0,00 & $2,964 \mathrm{~B} \mathrm{~b}$ & $3,396 \mathrm{~A} \mathrm{a}$ & $2,7647 \mathrm{~A} \mathrm{a}$ & $2,3871 \mathrm{Bb}$ \\
\hline 0,006 & $3,652 \mathrm{~A} \mathrm{a}$ & $3,279 \mathrm{~A} \mathrm{a}$ & $2,4444 \mathrm{~B} \mathrm{a}$ & $2,6666 \mathrm{~A} \mathrm{a}$ \\
\hline
\end{tabular}

Médias seguidas de mesma letra, maiúscula (coluna) e minúscula (linha), não diferem entre si, pelo teste de Tukey, a 5\% de probabilidade.

TABELA 4 - Médias referentes a grau de oxidação de explantes de bananeira-Prata (Musa AAB em relação a diferentes concentrações de ferro e cobre, e ferro e zinco. Goiânia-GO, 1999.

\begin{tabular}{|c|c|c|c|c|}
\hline \multirow{3}{*}{$\begin{array}{c}\text { Ferro } \\
\left(\mathrm{mg} \mathrm{L}^{-1}\right)\end{array}$} & \multicolumn{4}{|c|}{ Grau de Oxidação } \\
\hline & \multicolumn{2}{|c|}{ Cobre $\left(\mathrm{mg} \mathrm{L}^{-1}\right)$} & \multicolumn{2}{|c|}{ Zinco $\left(\mathrm{mg} \mathrm{L}^{-1}\right)$} \\
\hline & 0,00 & 0,006 & 0,00 & 1,96 \\
\hline 0,00 & $2,0000 \mathrm{a}$ & $2,2727 \mathrm{a}$ & $2,5454 \mathrm{a}$ & $1,7143 \mathrm{~b}$ \\
\hline 2,79 & $2,7727 \mathrm{a}$ & $2,2857 \mathrm{~b}$ & $2,4762 \mathrm{a}$ & $2,5909 \mathrm{a}$ \\
\hline 5,58 & $2,9545 \mathrm{~b}$ & $3,4286 \mathrm{a}$ & $2,8889 \mathrm{~b}$ & $3,3889 \mathrm{a}$ \\
\hline
\end{tabular}

Médias seguidas de letras iguais, na mesma linha, não diferem entre si, pelo teste de Tukey, a 5\% de probabilidade. 


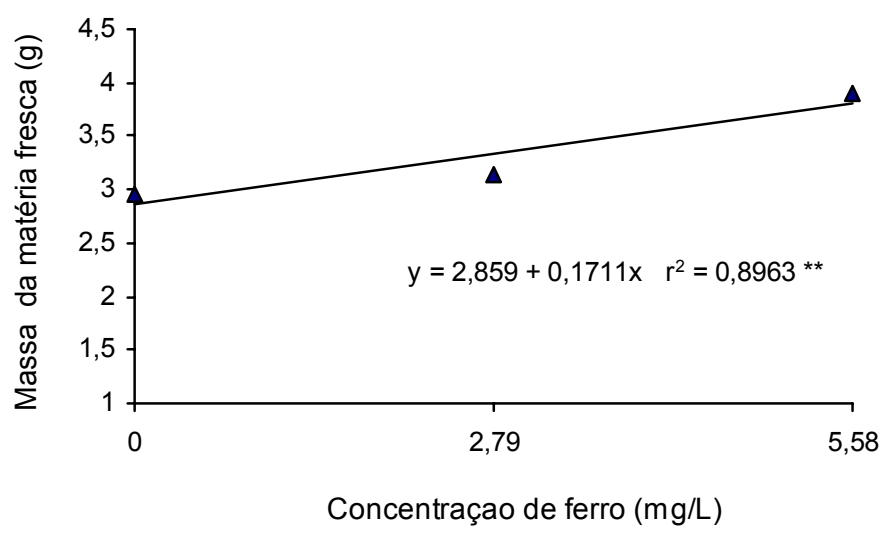

FIGURA 1 - Média da massa da matéria fresca de explantes de bananeira-Prata (Musa AAB) cultivadas in vitro em diferentes concentrações de $\mathrm{Fe}$ do meio de cultura. Goiânia-GO, 1999.

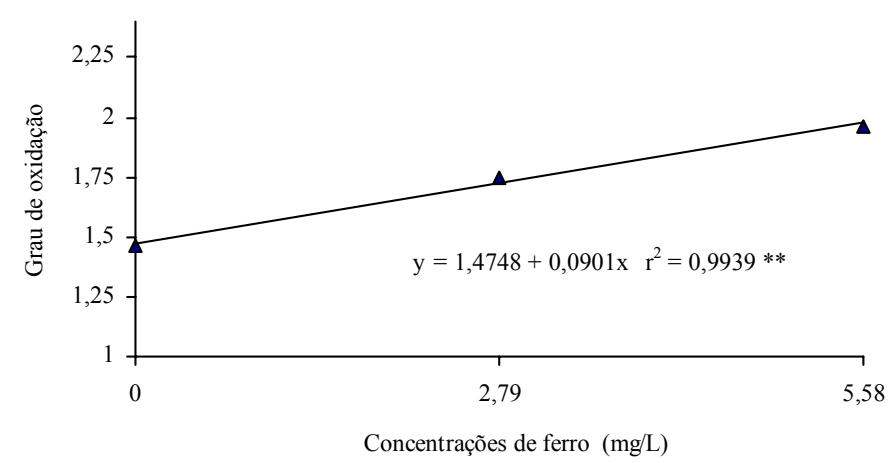

FIGURA 3 - Grau de oxidação ${ }^{1 /}$ de explantes de bananeira-Prata (Musa AAB) na presença de zinco $\left(1,96 \mathrm{mg} \mathrm{L}^{-1}\right)$ e em diferentes concentrações de ferro. GoiâniaGO, 1999.

${ }^{1 /}$ Dados transformados por $(\mathrm{x}+0,5)^{1 / 2}$

significativo sobre o grau de oxidação dos explantes. Quando se utilizou a concentração de $5,58 \mathrm{mg} \mathrm{L}^{-1}$ de $\mathrm{Fe}$, a oxidação foi maior na ausência de $\mathrm{Cu}$ (Tabela 4). Observou-se que existe uma tendência de aumento no grau de oxidação quando se aumenta a concentração do ferro, tanto na presença como na ausência de cobre. A análise de regressão para o efeito de diferentes concentrações de ferro, quando o cobre não foi adicionado ao meio de cultura sobre o grau de oxidação dos explantes, mostra um efeito linear crescente à medida que se eleva a concentração de ferro no meio de cultura (Figura 2). Segundo Vagera \& Havränek (1982), quando se adiciona Fe.EDTA ao meio de cultura, este tem relação direta com o escurecimento; entretanto, não foi verificada esta relação com a adição de $\mathrm{FeSO}_{4}$ ou EDTA , de forma isolada. A maior absorção de Fe pelo explante pode induzir a maior produção das enzimas peroxidase e catalase, as quais apresentam o ferro no grupo prostético (Araujo, 1995, e Pasqual et al., 1997). Estas aumentam a sua atividade na presença de oxigênio após sua liberação para o meio de cultura pelos tecidos lesados, o que provoca o aumento do escurecimento dos explantes (Amorim, 1985).

Os efeitos da interação ferro $\mathrm{x}$ zinco sobre o grau de oxidação dos explantes e a comparação de médias são mostradas na Tabela 4. Para a concentração de $1,96 \mathrm{mg} \mathrm{L}^{-1} \mathrm{de} \mathrm{Zn}$, verificouse que houve uma resposta linear em função das diferentes

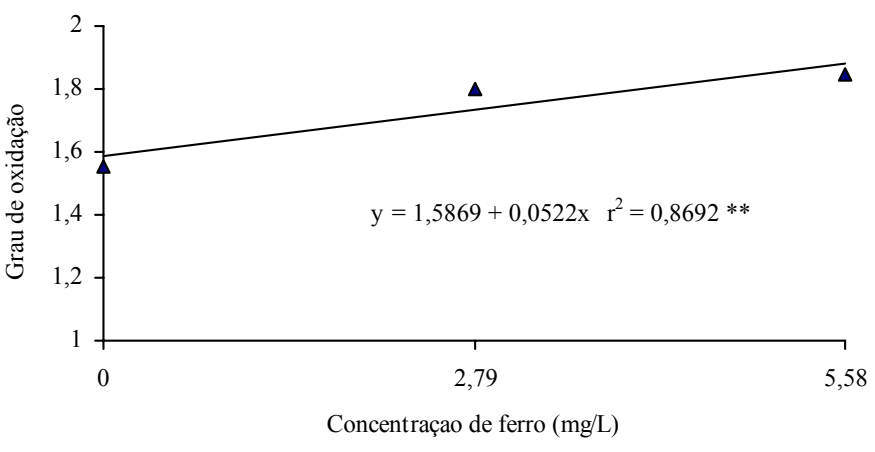

FIGURA 2 - Grau de oxidação ${ }^{1 /}$ de explantes de bananeira-Prata (Musa AAB) em diferentes concentrações de Fe, na ausência de Cu. Goiânia-GO, 1999.

${ }^{1 /}$ Dados transformados por $(\mathrm{x}+0,5)^{1 / 2}$

concentrações de ferro, ou seja, o grau de escurecimento dos explantes cresce à medida que se aumenta a sua concentração (Figura 3). Vagera \& Havränek (1982) verificaram que a intensidade do escurecimento aumentou proporcionalmente com a concentração de FeEDTA no meio. Verifica-se que o $\mathrm{Fe}$ influenciou positivamente sobre o grau de escurecimento dos explantes, tanto na ausência como na presença de $\mathrm{Zn}$, apresentando valores de 2,89 e 3,39, respectivamente, quando a dose de Fe foi maior. Pelos resultados apresentados na Tabela 4, verifica-se que, mesmo reduzindo o $\mathrm{Zn}$ e o Fe do meio de cultura, os explantes ainda se apresentaram escurecidos, ou seja, outros estudos devem ser realizados para obtenção de resultados mais expressivos.

\section{CONCLUSÕES}

1- O ferro, o cobre e o zinco não devem ser retirados do meio de cultura MS, pois são essenciais para o crescimento dos explantes. 2 - A concentração de ferro influencia a oxidação de explantes, sendo que maiores oxidações foram observadas em soluções mais concentradas.

3 - A redução ou retirada do $\mathrm{Cu}, \mathrm{Fe}$ e $\mathrm{Zn}$ do meio $\mathrm{MS}$, de forma isolada ou em combinações, não foi suficiente para eliminar a oxidação de explantes.

\section{REFERÊNCIAS BIBLIOGRÁFICAS}

AMORIM, H.V. de. Respiração. In: FERRI, M.G. (Coord.) Fisiologia vegetal. São Paulo : EPU, 1985. v.1, p.251-279.

ARAUJO, J.M.A. Química de alimentos: teoria e prática. Viçosa: UFV, 1985. 355 p.

CARNEIRO, I.F Adequação de técnicas de cultura in vitro da obtenção de mudas de bananeira (Musa AAB) cultivar Maçã. 1997 f. 106f. Tese (Doutorado) - Universidade Federal de Goiás, Goiânia, 1997. 
CEASA-GO. Aspectos da oferta e comercialização em 1996. Goiânia: CEASA, 1996. 175p. (Boletim Informativo, 21).

DECHEN, A.R.; HAAG, H.P.; CARMELLO, Q.A.C. Funções de micronutrientes na Agricultura. In: FERREIRA, A.A.; CRUZ, M.C.P. (Ed.). Micronutrientes na agricultura. Piracicaba: POTAFOS,1991. p. 169-172.

DINIZ, J.D.N.; GONÇALVES, A.N.; HERNANDEZ, F.F.F.; TORRES, A.C. Absorção de micronutrientes por explantes de bananeira in vitro. Pesquisa Agropecuária Brasileira, Brasília, v.34,n.8,p.1385-1391,1999.

GEORGE, E.F.; SHERRINGTON, P.D. Plant propagation by tissue culture. Hants: Exegetics Limited, 1984. 709p.

IBGE. Anuário estatístico do Brasil. Rio de Janeiro, 1998. v.58, p.3-26.

MALAVOLTA, E.; HAAG, H.P.; MELLO, F.A.F. et al.. Nutrição mineral e adubação de plantas cultivadas. São Paulo : Pioneira, 1974. 752p.

MENGEL, K.; KIRKBY, E.A. Principles of plant nutrition. Bern: Potash Institute, 1987. 685p.
MURASHIGE, T.; SKOOG, F. A revised medium for rapid growth and bio assays with tobacco tissue cultures. Physiologia Plantarum, Copenhagen, v.15, p.473-497, 1962.

PASQUAL , M.; HOFFMANN, A.; RAMOS, J.D. Cultura de tecidos vegetais: tecnologia e aplicação. Lavras: UFLA, 1997. $159 \mathrm{p}$.

SOUZA, A. S.; DANTAS, J.L.L.; SOUZA, B.F.V.; CORDEIRO,Z.J.M.; SILVA NETO, S.R.S. Propagação. In: ALVES, E.J. org. A cultura da banana. Aspectos técnicos, socioeconômicos e agroindustriais. Cruz das Almas:Embrapa/ SPI, 1998.p.151-195.

VAGERA, J.; HAVRÁNEK, P. In vitro regulation of androgenesis by iron ions and chelate: a common property of two androgenic species (Nicotiana tabacum L. and Datura innoxia Mill). Biologia Plantarum, Praga, v.24, n.4, p.282-289, 1982.

VUYLSTEKE, D.R.; ORTIZ, R. Field perfomance vs. in vitro propagules of plantain (Musa spp., AAB GROUP). HortScience, Alexandria, v.31, n.5, p.862-865, 1996. 